\title{
Electrochemical assessment of water|ionic liquid biphasic systems towards cesium extraction from nuclear waste
}

\author{
T. Jane Stockmann ${ }^{\mathrm{a}, \mathrm{b}}$, Jing Zhang ${ }^{\mathrm{b}}$, Anne-Marie Montgomery ${ }^{\mathrm{b}}$, Zhifeng Ding ${ }^{\mathrm{b}, *}$ \\ a Laboratoire d'Electrochimie Physique et Analytique, Ecole Polytechnique Fédérale de Lausanne (EPFL), Station 6, Lausanne CH-1015, Switzerland \\ b Department of Chemistry, The University of Western Ontario, 1151 Richmond Street, London, Ontario N6A 5B7, Canada
}

\section{H I G H L I G H T S}

- Electroanalytical chemistry was employed to assess cesium ion extraction in biphasic systems.

- Water|ionic liquid systems are much more efficient than traditional water| organic ones.

- The metal ion to ligand stoichiometry and overall complexation constant were determined.

- The stoichiometry was confirmed by mass spectrometry.

- The ligand CMPO used in TRUEX processes was found to be effective for the FIT.

\section{G R A P H I C A L A B S T R A C T}
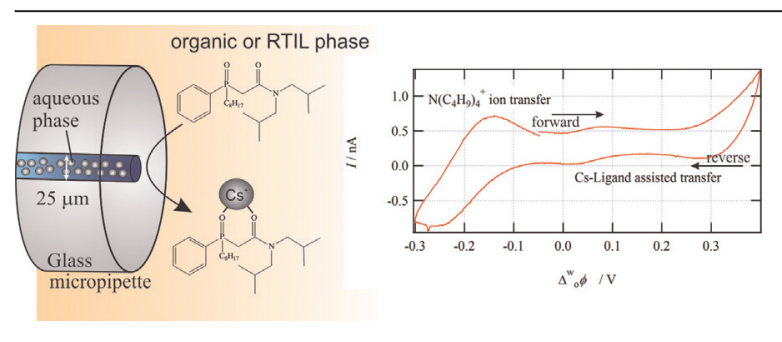

\section{A R T I C L E I N F O}

\section{Article history:}

Received 4 January 2014

Received in revised form 9 March 2014

Accepted 11 March 2014

Available online 14 March 2014

\section{Keywords:}

Ionic liquids for electroanalytical chemistry Ion transfer at microinterfaces

Cesium extraction from spent nuclear fuel

Ligand in TRans-Uranium EXtraction processes

Mass spectrometry for stoichiometry

\begin{abstract}
A B S T R A C T
A room temperature ionic liquid (IL) composed of a quaternary alkylphosphonium (trihexyltetradecylphosphonium, $\mathrm{P}_{66614}{ }^{+}$) and tetrakis(pentafluorophenyl)borate anion $\left(\mathrm{TB}^{-}\right.$) was employed within a water| $\mathrm{P}_{66614} \mathrm{~TB}\left(\mathrm{w} \mid \mathrm{P}_{66614} \mathrm{~TB}\right.$ or $\left.\mathrm{w} \mid \mathrm{IL}\right)$ biphasic system to evaluate cesium ion extraction in comparison to that with a traditional water|organic solvent $(\mathrm{w} \mid \mathrm{o})$ combination. ${ }^{137} \mathrm{Cs}$ is a major contributor to the radioactivity of spent nuclear fuel as it leaves the reactor, and its extraction efficiency is therefore of considerable importance. The extraction was facilitated by the ligand octyl(phenyl)-N,N'-diisobutylcarbamoylphosphine oxide (CMPO) used in TRans-Uranium EXtraction processes and investigated through well established liquid|liquid electrochemistry. This study gave access to the metal ion to ligand (1:n) stoichiometry and overall complexation constant, $\beta$, of the interfacial complexation reaction which were determined to be $1: 3$ and $1.6 \times 10^{11}$ at the $\mathrm{w} \mid \mathrm{P}_{66614} \mathrm{~TB}$ interface while the study at $\mathrm{w} \mid \mathrm{o}$ elicited an $n$ equal to 1 with $\beta$ equal to 86.5 . Through a straightforward relationship, these complexation constant values were converted to distribution coefficients, $\delta_{\alpha}$, with the ligand concentrations studied for comparison to other studies present in the literature; the w|o and w|IL systems gave $\delta_{\alpha}$ of 2 and $8.2 \times 10^{7}$, respectively, indicating a higher overall extraction efficiency for the latter. For the w|o system, the metal ion-ligand
\end{abstract}

Abbreviations: CE, counter electrode; CV, cyclic voltamogramms; ESI-MS, electrospray ionization mass spectroscopy; FIT, facilitated ion transfer; IL, ionic liquid; IT, ion

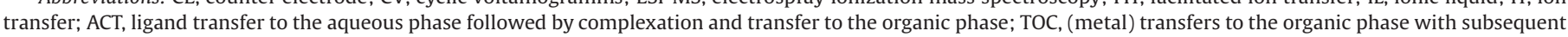

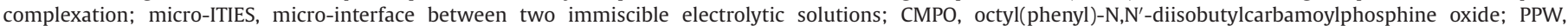

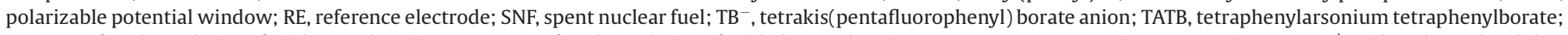

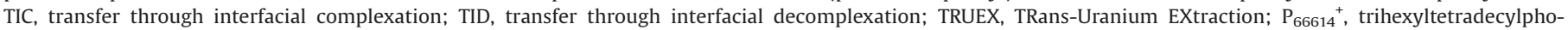
sphonium; w|DCE, water|1,2-dichloroethane; w|o, water|organic solvent; $w \mid \mathrm{P}_{66614} \mathrm{~TB}$ or $\mathrm{w} \mid \mathrm{IL}$, water| $\mid \mathrm{P}_{66614} \mathrm{~TB}$; WE, working electrode.

* Corresponding author. Tel: +1 519661 2111x8616; fax: +1 5196613022.

E-mail addresses: zfding@uwo.ca, http://publish.uwo.ca (Z. Ding). 
stoichiometries were confirmed through isotopic distribution analysis of mass spectra obtained by the direct injection of an emulsified water-organic solvent mixture into an electron spray ionization mass spectrometer.

\section{Introduction}

Room temperature ionic liquids (ILs), large organic salts with melting points below $100^{\circ} \mathrm{C}$, have attracted a great deal of attention over the past decade with the development of air and water stable versions. The increased interest is due in no small part to their unique properties including a high electrochemical stability that gives rise to large potential windows [1-3], but with a distinct interfacial structure [4-8]. This, in conjunction with ILs low volatility, non-flammability, and high thermal stability make them desirable solvents for a variety of applications including sensors [9], lithium batteries [10,11], and in biphasic metal extraction [12-18]. ILs have shown marked improvement over conventional molecular solvents in many of these areas [13].

Interestingly, ILs incorporating quaternary phosphonium cations, such as trihexyltetradecylphosphonium $\left(\mathrm{P}_{66614}{ }^{+}\right)$and tetraoctylphosphonium $\left(\mathrm{P}_{8888}{ }^{+}\right.$), have been found to possess higher electrochemical stability over ammonium- or imidazolium-based ILs [3], while they also demonstrate greater hydrophobicity $[19,20]$. Additionally, the tetrakis(pentafluorophenyl)borate anion $\left(\mathrm{TB}^{-}\right)$has been shown to have good electrochemical stability [21], excellent hydrophobicity [19,20,22], and, critically, low ion-pair interactions [21-23]. Combining these cations and anions generates ILs with excellent physicochemical and electrochemical properties to make them ideally suited, not only in the role of conventional supporting electrolytes, but also as alternative solvents in biphasic metal ion extractions [13] for spent nuclear fuel (SNF) reprocessing.

Recently, ILs combining quaternary alkyl phosphonium cations with $\mathrm{TB}^{-}$have been prepared to explore their implications in biphasic separations towards SNF reclamation [19,20]. Typically, metal ion extractions are characterized by first mechanically mixing the two phases and then determining the amount of metal ions distributed between the two phases $[13,24]$. Where these methods differ is in the analysis of metal ion distribution between the phases. Some techniques employ radioisotopes and absorption spectroscopy [25] or inductively coupled plasma (ICP) spectroscopy [18], which can be expensive and require a specialized laboratory or handling procedures.

Electrochemistry at a micro-interface between two immiscible electrolytic solutions (micro-ITIES) offers a cost-effective technique for studying metal ion transfer (IT) and ligand assisted, or facilitated ion transfer (FIT) [12,14,26-28], which are analogous to ion partitioning and interfacial complexation, respectively. These respective processes are shown in Eqs. (1) and (2) for the general case of an ion, $i$, of charge $z$ transferring from water, $w$, to an organic, o, phase:

$i_{\mathrm{w}}^{z} \rightleftharpoons i_{\mathrm{o}}^{z}$

$i_{\mathrm{w}}^{z}+n L_{\mathrm{o}} \rightleftharpoons i L_{n, 0}^{z}$

Whereas for FIT, a ligand, L, is added to the organic (or IL) phase and coordinates to the metal ion center interfacially with a metal to ligand stoichiometry of $1: n$. The mechanism described in Eq. (2) is commonly referred to as transfer through interfacial complexation (TIC) with the return process termed transfer through interfacial decomplexation (TID); however, two other mechanisms are possible [29]. In one scenario the metal transfers to the organic phase with subsequent complexation (TOC), while another pathway is through ligand transfer to the aqueous phase followed by complexation and transfer to the organic phase, often abbreviated as ACT [29].

ITIES or biphasic electrochemistry has been the subject of many reviews [30-33]. The so-called soft interface is a vital electrochemical technique, which has been used for biomimetic studies of oxygen reduction catalyzed by metalloporphyrins [34] and metalfree porphyrins [35], IT and ion absorption studies at microhole arrays utilizing a liquid|organo-gel interface with possible sensor applications [36-38], kinetic investigations of pharmaceutical micro-extraction/transfer $[39,40]$, along with nano-pore investigations [41]. These examples simply serve to demonstrate the farreaching implications and impact of this methodology.

Herein, octyl(phenyl)-N, $\mathrm{N}^{\prime}$-diisobutylcarbamoylphosphine oxide (CMPO), a ligand employed industrially in the TRans-Uranium EXtraction (TRUEX) processes [25], has been used, along with the ionic liquid, $\mathrm{P}_{66614} \mathrm{~TB}$, as a model system to demonstrate the use of ILs in metal extraction at electrified biphasic interfaces. Owing to the hydrophobic character of CMPO, only the TIC/TID mechanism has been considered.

FIT can be characterized by electrochemistry such that the overall complexation constant, $\beta$, and metal to ligand ratio, $1: n$ can be determined [28]. This technique was pioneered by Samec, Mareček et al. [42], Kakiuchi and Senda [43], and Girault et al. [28] for water|organic $(\mathrm{w} \mid \mathrm{o})$ interfaces and recently for water|IL (w|IL) interfaces $[12,14,16,44]$.

Cesium was chosen as ${ }^{137} \mathrm{Cs}$ is a common fission byproduct that contributes greatly to the radioactivity and thermal heat of SNF (in conjunction with ${ }^{90} \mathrm{Sr}$ ) [45], while also having well established free metal ion transfer characteristics studied at $\mathrm{w} \mid 1,2$-dichloroethane ( $w \mid D C E), w \mid$ nitrobenzene, and $w \mid P_{66614} \mathrm{~TB}[22,46-49]$. These two factors should elicit interest from the nuclear community [50].

\section{Experimental}

\subsection{Chemicals}

All chemicals were purchased as reagent grade or higher and used as received without further purification. Cesium nitrate $\left(\mathrm{CsNO}_{3}\right)$, cesium chloride $(\mathrm{CsCl})$, tetrabutylammonium chloride (TBACl), 1,2-dichloroethane (DCE), and dichloromethane were obtained from Sigma-Aldrich Canada Ltd. (Mississauga, ON). Trihexyltetradecylphosphonium chloride $\left(\mathrm{P}_{66614} \mathrm{Cl}\right)$ was bought from Strem Chemical Inc. (Newburyport, MA) while potassium tetrakis(pentafluorophenyl) borate (KTB) was ordered from Boulder Scientific Company (Mead, CO). $\mathrm{P}_{66614}$ TB was prepared through the metathesis of $\mathrm{P}_{66614} \mathrm{Cl}$ with KTB in dichloromethane; this procedure, along with purification steps, has been described in detail elsewhere $[19,20]$.

\subsection{Micropipette fabrication}

A few of our recent publications describe the micropipette fabrication $[19,20,46]$; however, a brief outline follows. A borosilicate glass capillary $(1.0 \mathrm{~mm} / 2.0 \mathrm{~mm}$ internal/external diameter, Sutter Instrument Co., Novato, CA, USA) was fixed inside a Narishige electric puller (Model \#PP-83, Japan) with the capillary centered around the pullers heating coil. Upon heating and pulling, 
two capillaries with tapered ends were generated; a Bunsen burner was used to flame-anneal the tapered ends that were sealed. Through the open end, a 1.0 to $1.5 \mathrm{~cm}$ length of Pt-wire $(25 \mu \mathrm{m}$ in diameter, Goodfellow Cambridge Ltd., Huntingdon, United Kingdom) was loaded into the capillary and, with care, dropped down into the tapered end. Under vacuum (a small hose was attached to the open end of the capillary), the Pt-wire was sealed in 0.5 to $1.5 \mathrm{~mm}$ of glass using the electric puller. A cross-section of the Pt-wire was then revealed through polishing with a series of grinding/polishing pads (Buehler Canada, Markham, ON); the surface is routinely checked with an optical microscope to ensure the glass is smooth and free of defects. Polishing is considered complete when the $R_{g}$, ratio of external $\left(r_{g}\right)$ to internal $(a)$ diameter $\left(R_{g}=r_{g} / a\right)$, was greater than 50 and the length of sealed Pt-wire was between 250 and $500 \mu \mathrm{m}$. The Pt-wire was then removed through immersion in aqua regia - a 3:1 solution of $\mathrm{HCl}: \mathrm{HNO}_{3}$. Silanizing the tip of the capillary was found to improve interfacial stability. This was achieved by dipping the tip into trimethylchlorosilane. Argon gas was bubbled through the back of the capillary to make sure no internal silanization took place. Afterwards, the capillary was dried and baked overnight in an oven at $100^{\circ} \mathrm{C}$.

\subsection{Electrochemistry}

All electrochemical measurements were performed using the Modulab system from Solatron Analytical (Ametek Advanced Measurement Technology, Farnborough, New Hampshire) incorporating a femto ammeter. The working electrode (WE) was fitted with a BNC adaptor and attached to a modified HEKA micropipette holder (HEKA Electronics, Mahone Bay, NS) containing an integrated silver wire held within the aqueous phase that was maintained inside the capillary. The counter (CE) and reference electrode (RE) leads were coupled together and clipped to another silver wire which was placed in the organic or $\mathrm{P}_{66614} \mathrm{~TB}$ phase. Two biphasic cells were employed and are given schematically below:

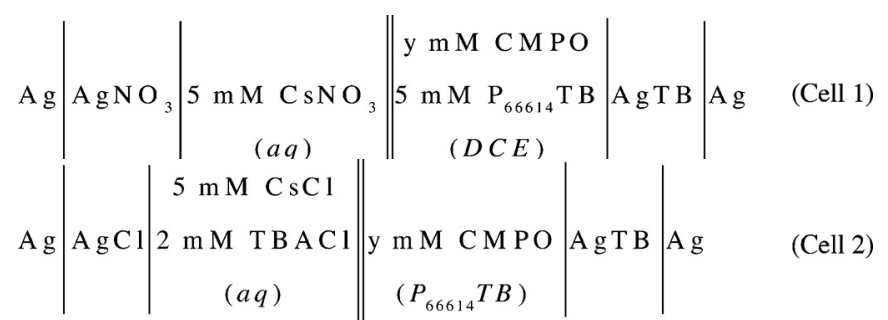

All w|DCE measurements were conducted at room temperature; however, all IL experiments were performed at $60^{\circ} \mathrm{C}$ in order to reduce the IL viscosity [19]. Additionally, in order to ensure that the micro-interface was maintained at the tip of the pipette, the microITIES was monitored continuously using a CCD camera (Motic Inc., Richmond, BC) attached to a $12 \times$ zoom lens assembly (Navitar, Rochester, NY) and linked to a desktop computer via a USB cable. The ITIES position could be adjusted using a syringe incorporated into the design of the micropipette holder. The holder has previously been described [12,51].

\subsection{Electrospray ionization mass spectroscopy (ESI-MS)}

All mass spectra were obtained using a Micromass LCT (Waters, Milford, MA) in the positive ion mode with the following instrument parameters: capillary, sample cone, and extraction cone voltage of 5000,42 , and $0 \mathrm{~V}$ along with a sampling time, scan time, and interscan delay of $5 \mathrm{~min}, 4 \mathrm{~s}$, and $0.1 \mathrm{~s}$. The spectrum ranged from 80 to $2000 \mathrm{~m} / \mathrm{z}$. Solutions were loaded into a $250 \mu \mathrm{L}$ syringe (Hamilton Co., Reno, NV) and placed in a syringe pump set at $25 \mu \mathrm{Lmin}^{-1}$.

\section{Results and discussion}

\subsection{Facilitated ion transfer of $\mathrm{CS}^{+}$with $C M P O$ at $w \mid D C E$ micro-ITIES}

Fig. 1 shows an overlay of cyclic voltammograms (CVs) acquired at a w|DCE interface utilizing Cell 1 with $5 \mathrm{mM}$ of $\mathrm{CsNO}_{3}$ in the aqueous phase while varying the concentration of CMPO in the organic phase.

Trace a in Fig. 1 illustrates electrochemical behaviour of the Cell 1 with no ligand added $(y=0)$ in the organic phase or a 'blank' solution. The CV was initiated at $0.000 \mathrm{~V}$ and swept in the forward direction - towards more positive potentials relative to the water phase - at a rate of $0.025 \mathrm{~V} \mathrm{~s}^{-1}$. The rise in the current response at $0.448 \mathrm{~V}$ marks the edge of the polarizable potential window (PPW) and corresponds to the free or simple IT of cesium cations from the water to organic phase ( $w$ to o) and back (o to $w$ ) during the reverse scan to $0.000 \mathrm{~V}$ [46]. Aside from current increase at the limit of the PPW, a featureless curve is generated that is demonstrative of no additional IT or ligand assisted/FIT. After addition of CMPO, however, the current-potential response undergoes a significant change. It is important to note that the PPW scanned in trace a is smaller than that employed for the ligand added cases (traces b-f); this was intentional. As demonstrated recently, free alkali metal IT can be observed; however, this results in the massive transfer of ions that can undermine interfacial stability [46].

During the forward sweep of trace b in Fig. 1 with $y=22 \mathrm{mM}$, from 0.000 to $0.641 \mathrm{~V}$, a peak-shaped wave can be observed at $0.485 \mathrm{~V}$. During the reverse scan, from 0.641 to $0.000 \mathrm{~V}$, an "s"shaped or sigmoidal wave can be observed with a half-wave potential of $0.330 \mathrm{~V}$. This CV profile is in good agreement with the FIT of potassium by dibenzo-18-crown-6 at a micro-ITIES investigated by Shao et al. [52].

The peak-shaped wave on the forward scan and the sigmoidal wave on the reverse are a direct result of the pipette geometry. During TIC, the $\mathrm{Cs}^{+}$in a solution of small volume within the microchannel is quickly consumed generating a rapid increase in the current-potential response followed by exponential decay. This is sometimes called linear diffusion owing to the limited direction ions can travel within the microchannel. However, it is also referred to as being under 'consumption' control because of the peak-shaped waves dependence on the square root of the scan rate $(v)$ according to the Randles-Sevčik equation [53,54]:

$i_{p}=0.4463\left(\frac{F^{3}}{R T}\right)^{1 / 2} z^{3 / 2} A D_{i, \alpha}^{1 / 2} c_{i, \alpha}^{*} v^{1 / 2}$

where $F, R, T, n$, and $A$ are Faraday's constant, universal gas constant, temperature (in Kelvin), charge, and the surface area of the liquid| liquid interface, respectively. $D_{i, \alpha}$ and $c_{i, \alpha}^{*}$ are the diffusion coefficient and the initial concentration of species $i$ in phase $\alpha$, respectively. Eq. (3) was developed for large (millimeter or centimeter) metal-solution interfaces and is used here as an approximation.

The sigmoidal wave of TIC is the result of hemispherical diffusion because the flux of ions to the interface can occur from a relatively large hemispherical volume surrounding the ITIES, which elicits a rise in current followed by a plateau. In this way, the FIT observed is in good agreement with established theory surrounding ion transfer at an ITIES housed at the tip of a pulled capillary [55] and with that presented recently [12,14,27].

Interestingly, as the concentration of CMPO in the organic phase is increased this peak shifts to more negative potentials. With $y$ equal to $43,62,80$, and $96 \mathrm{mM}$ for curves c, d, e, and f, the peak associated with FIT shifts to $0.479,0.467,0.461$, and $0.450 \mathrm{~V}$, respectively. As the concentration of ligand in the organic phase increases, this causes a reduction in the amount of applied 


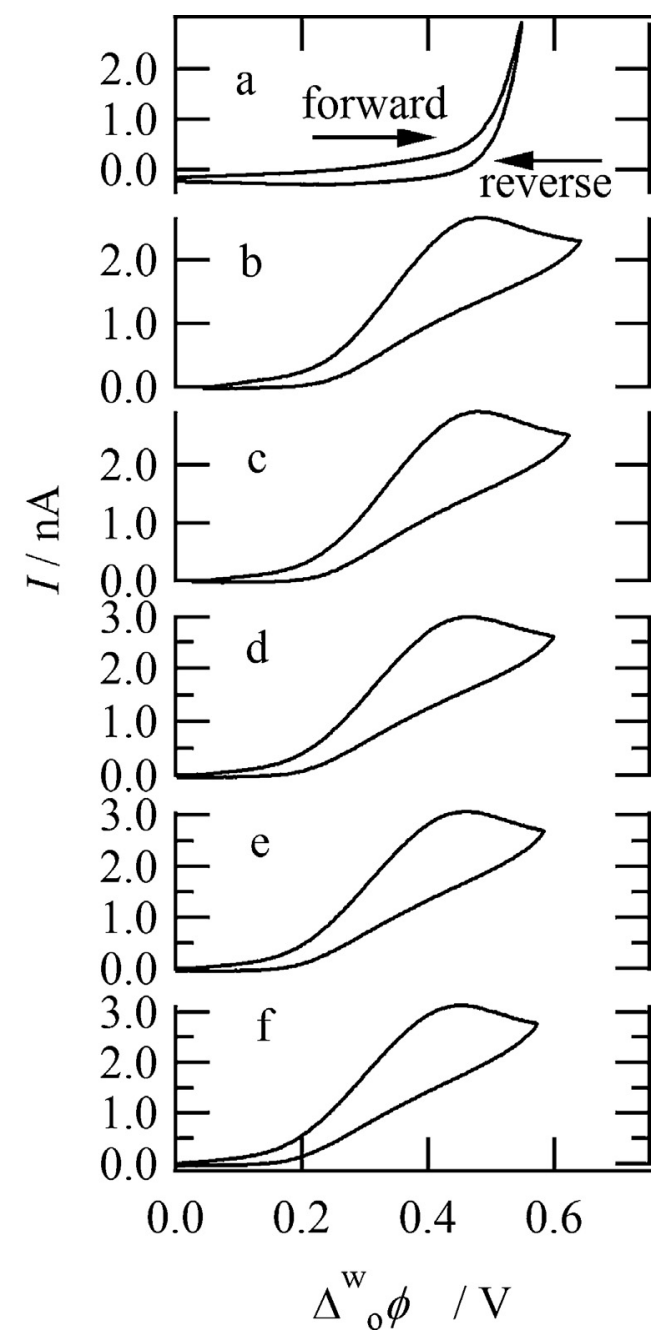

Fig. 1. Cyclic voltamogramms acquired using Cell 1 with a CMPO concentration $(y)$ equal to $0,22,43,62,80$, and $96 \mathrm{mM}$, for curves a, b, c, d, e, and f, respectively, at a scan rate of $0.025 \mathrm{~V} \mathrm{~s}^{-1}$.

potential required to elicit ion transfer. Thus, the CVs overlaid in Fig. 1 agree well with the theory of FIT [28]. This can be further elucidated through the following equation [28].

$-\frac{z F}{R T}\left(\Delta_{o}^{w} \phi_{i L_{n}^{z^{+}}}^{o^{\prime}}-\Delta_{o}^{w} \phi_{i^{z^{+}}}^{o^{\prime}}\right)=n \ln \left(c_{\text {init. }}\right)+\ln (\beta)+\ln (\xi)$

The formal IT potential of the metal ion-ligand complex, $\Delta_{o}^{w} \phi_{i L_{n}^{o^{\prime}} \text {, }}$ was obtained directly from its CV. $\Delta_{o}^{w} \phi_{i^{\prime}}^{o^{\prime}}$ is the formal IT potential of the free metal ion, which is a constant unique to each metal ion and biphasic system; this was taken to be $0.480 \mathrm{~V}$ [22]. The variables $n, c_{L, 0}^{*}$, and $\beta$, are the metal to ligand stoichiometry $(1: n)$, initial ligand concentration, and overall complexation constant, respectively. Please note that CMPO is quite hydrophobic and thus its partitioning to the aqueous phase should be low. In this way, by varying the initial concentration of the ligand and plotting the potential differences $\operatorname{vs} \cdot \ln \left(c_{L, o}^{*}\right)$, a linear relationship can be developed such that the slope is the metal to ligand stoichiometry whilst the $y$-intercept can be used to elucidate the overall complexation constant. The final term in Eq. (4), $\xi$, is equal to $\sqrt{D_{i, 0} / D_{i, w}}$; for the $\mathrm{w} \mid \mathrm{DCE}$ case, the diffusion coefficients in each phase were considered equal and thus the term was reduced to 0 .

The potential scale has been calibrated using the tetraphenylarsonium tetraphenylborate (TATB) [56], or Parker's [57] assumption which use well established IT potentials of simple ions, such as tetramethylammonium $\left(\mathrm{TMA}^{+} ; 0.160 \mathrm{~V}\right.$ [58]) or nitrate $\left(\mathrm{NO}_{3}{ }^{-}\right.$; $-0.380 \mathrm{~V}[46])$, as internal standards. The half-wave potentials were determined from the peak potential, $\Delta_{o}^{w} \phi_{p}$, and the relation, $\Delta_{o}^{w} \phi_{1 / 2, i L_{n}^{z+}}=\Delta_{o}^{w} \phi_{p} \pm 0.028 \mathrm{~V} / z$, as described in Bard and Faulkner $[53,54]$.

Applying this methodology to the CV data illustrated in Fig. 1, one can arrive at the linear graph displayed in Fig. 2A. The linear regression results are listed as an inset in Fig. 2A such that the slope is 1 , the $y$-intercept is 4.46 , and the $R^{2}$ is 0.971 . If the diffusion coefficients in the organic and aqueous phases are assumed to be approximately equivalent, then Eq. (4) can be simplified and $\ln \beta_{n}$ directly extrapolated; in this case $\beta_{n}$ is 86.5 . The relatively high $R^{2}$ value, 0.971 , shows a satisfactory linear trend.

A proposed structure of $\mathrm{CsCMPO}^{+}$with three water molecules is drawn in Fig. 2B demonstrating a possible octahedral geometry. CMPO coordinates predominantly to the metal ions through the oxygens on the carbamoyl or phosphine oxide groups, while the latter is the most preferred [15,59]. Alkali ligand coordination chemistry is presented extensively in the literature, with the state of research being reviewed annually [60]. Cesium coordination numbers (c.n.) can be high when considering the ubiquitous dibenzo-crown-ether series of ligands, generating c.n. equal to 6 or, in the case of sandwich compounds, 12 or higher [61,62]. Comparatively, the electrochemistry detailed herein points to only one CMPO and, therefore a maximum c.n. of 2. Recent studies of dioxouranium, strontium, and rubidium FIT describe the coordination of these metals with w|DCE ligand stoichiometries $[12,14,27]$ of 2 or 3 ; therefore, the result for $\mathrm{Cs}^{+}$was highly feasible. In fact the low Cs:CMPO ratio is a result of the decreased hydrophilicity of cesium, relative to other alkali and alkali earth metals, rather than its poor coordination [46,51]. Owing to the relatively high hydrophilicity of rubidium and strontium, they would require a higher number of ligands to elicit IT while cesium does not. Indeed, until recently cesium was one of the few alkali metal ions whose IT could be observed at the w|DCE interface $[58,63]$.

\subsection{Stoichiometry confirmation using electrospray ionization mass spectroscopy}

Fig. 3 illustrates the mass spectrum obtained through direct injection of an emulsified water-DCE biphasic mixture containing $20 \mathrm{mM} \mathrm{CsNO}_{3}$ and $100 \mathrm{mM} \mathrm{CMPO}$, respectively, into the electrospray ionization mass spectrometer (ESI-MS). In this experiment, $100 \mu \mathrm{L}$ of the cesium nitrate aqueous solution, along with $100 \mu \mathrm{L}$ of the DCE ligand solution, were placed in a small flask and shaken. Fig. 3 shows the four mass peaks of interest occurring at 132.9, 408.3, 540.2, and $947.5 \mathrm{~m} / \mathrm{z}$ corresponding to $\mathrm{Cs}^{+},[\mathrm{CMPO}+\mathrm{H}]^{+}$, $\left[\mathrm{CsCMPO}^{+}\right.$, and $\left[\mathrm{CsCMPO}_{2}\right]^{+}$, respectively. ${ }^{132.9} \mathrm{Cs}$ is the $100 \%$ abundant isotope of cesium [64] and thus its peak at $132.9 \mathrm{~m} / \mathrm{z}$ shows no perceivable distribution pattern. This also greatly simplifies the isotopic distribution analysis for the remaining peaks, which possess the typical descending mass pattern common to most hydrocarbons. This can be seen in the [CMPO + $\mathrm{H}]^{+}$mass peak, but more notably for the $\left[\mathrm{CsCMPO}^{+}\right.$and $\left[\mathrm{CsCMPO}_{2}\right]^{+}$, which are shown as magnified insets with their respective calculated distribution profiles displayed below. The experimental and calculated profiles are in excellent agreement.

These data generating a 1:1 metal ion to ligand stoichiometry, are in good agreement with that observed electrochemically, along with previous reports for rubidium [14] and strontium [12].

\subsection{Investigation of CS-FIT at the $w \mid P_{66614}$ TB interface}

Trace a in Fig. 4 illustrates the CV obtained at a w|IL microinterface using Cell 2 with no ligand added to the IL phase $(y=0)$. 


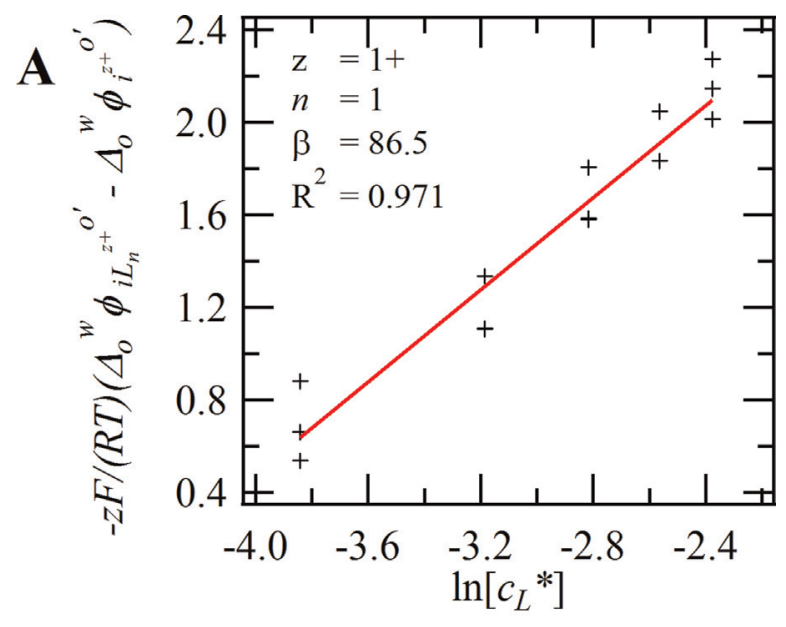

B

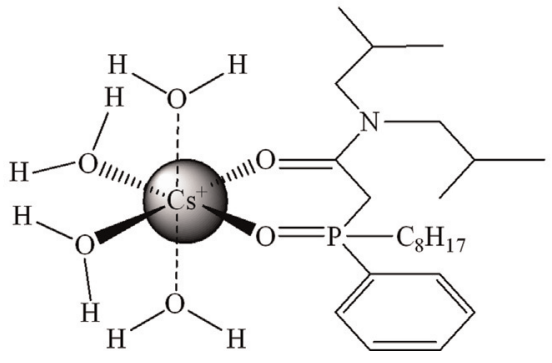

Fig. 2. (A) Graph of $-z F /(R T)\left(\Delta_{o}^{w} \phi_{i L^{z+}}^{o^{\prime}}-\Delta_{o}^{w} \phi_{i^{2+}}^{o^{\prime}}\right)$ versus $\ln \left[c_{L}^{*}\right]$ with, inset, linear regression data for the slope $(n=1)$ and $R^{2}=0.971$. (B) Proposed structure of CsCMPO with possible hydration sphere including $3 \mathrm{H}_{2} \mathrm{O}$ molecules creating an octahedral geometry.

The scan was initiated at approximately $-0.180 \mathrm{~V}$ and was swept at a rate of $0.020 \mathrm{~V} \mathrm{~s}^{-1}$ with a potential range from -0.250 to $0.575 \mathrm{~V}$. During the forward scan, a peak-shaped wave can be observed with a peak potential at $-0.018 \mathrm{~V}$; this is indicative of $\mathrm{TBA}^{+}$transfer from $\mathrm{w}$ to IL. The edge of the PPW was reached at $0.522 \mathrm{~V}$, upon which the scan direction was switched and proceeded towards negative potentials until $-0.256 \mathrm{~V}$. Within the reverse scan another peakshaped wave can be observed and is owing to the transfer of $\mathrm{TBA}^{+}$ back from the IL to $w$.

The w|IL interface is distinct from the w|DCE interface as the increased viscosity within the IL phase translates into a lower diffusion coefficient. Diffusion within the IL phase is slow enough

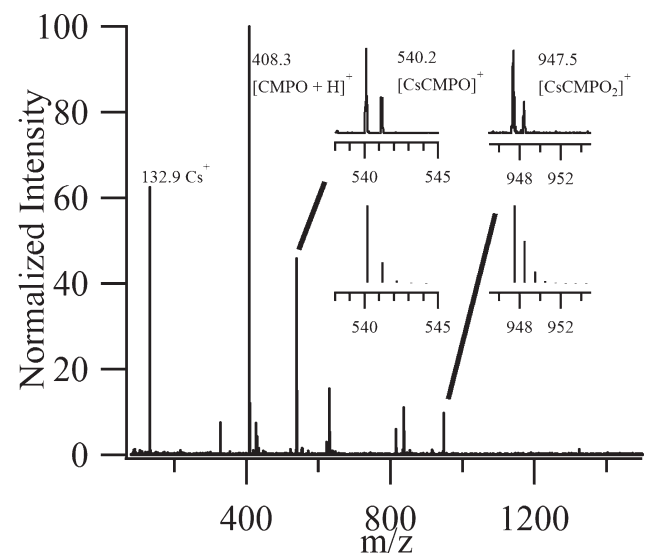

Fig. 3. Mass spectrum recorded through direct injection of an emulsified biphasic solution containing $100 \mathrm{mM}$ of CMPO in the DCE phase and $20 \mathrm{mM}^{\circ} \mathrm{CsNO}_{3}$ in the aqueous phase. Inset, above are magnified sections of the mass spectrum whilst below are calculated isotopic distributions for $\left[\mathrm{CsCMPO}^{+}(540.2 \mathrm{~m} / \mathrm{z})\right.$ and $\left[\mathrm{CsCMPO}_{2}{ }^{+}\right](947.5 \mathrm{~m} / \mathrm{z})$. that the mechanism of IT changes from hemispherical, or diffusion controlled, to linear, or consumption controlled; this is the primary reason that the reverse wave is peak-shaped and not sigmoidal as in the case of the w|DCE interface.

The IT of $\mathrm{TBA}^{+}$was used as the internal reference, with $\Delta_{\mathrm{IL}}^{w} \phi_{\mathrm{TBA}^{+}}^{o^{\prime}}=-0.173 \mathrm{~V}$, according to the TATB assumption [56,57]. The formal IT potential of $\mathrm{TBA}^{+}$at the $\mathrm{w} \mid \mathrm{P}_{66614} \mathrm{~TB}$ interface was determined relative to the IT of tetramethylammonium [19]. The TBA cation was chosen as it transfers towards the negative end of the PPW and, therefore allows for better observation of the possible $\mathrm{Cs}^{+}$-FIT peaks. Nitrate ion transfer has been used previously [14] for the study of rubidium FIT; however, employing only $\mathrm{CSNO}_{3}$ in the aqueous phase resulted in a physical instability in the ITIES when scanning to more negative potentials. Additionally, $\mathrm{CsCl}$ afforded a wider PPW as $\mathrm{Cl}^{-}$transfer is more negative.

Utilizing the same strategy employed at the w|DCE interface, the initial ligand concentration was then altered from $27 \mathrm{mM}$ to 48 , 62 , and $82 \mathrm{mM}$ for traces b, c, d, and e in Fig. 4 and, after the addition of the CMPO, a new peak appears with half-wave potentials at $0.243,0.203,0.166$, and $0.131 \mathrm{~V}$, respectively. Analogous to the $w \mid D C E$ case, increasing the ligand concentration lowers the amount of applied potential required to elicit charge transfer. Using Eq. (4), with $\Delta_{\mathrm{IL}}^{w} \phi_{\mathrm{Cs}^{\prime}}^{o^{\prime}}$ equal to $0.518 \mathrm{~V}$ [47], the effect of $-z F /(\mathrm{RT})\left(\Delta_{\mathrm{IL}}^{w} \phi_{\mathrm{CSCMPO}_{n}^{o^{\prime}}}-\Delta_{I L}^{w} \phi_{\mathrm{Cs}^{+}}^{o^{\prime}}\right)$ versus $\ln \left(c_{\mathrm{CMPO}}^{*}\right)$ was developed and illustrated in Fig. 5. Linear regression analysis revealed a satisfactory fitting with an $R^{2}$ of 0.9196 , a slope of 3, and a $y$-intercept of 21.65 .

This is interesting as it indicates 3 CMPO molecules participated in the interfacial complexation reaction, which translates to a higher overall complexation constant. Unfortunately, the high

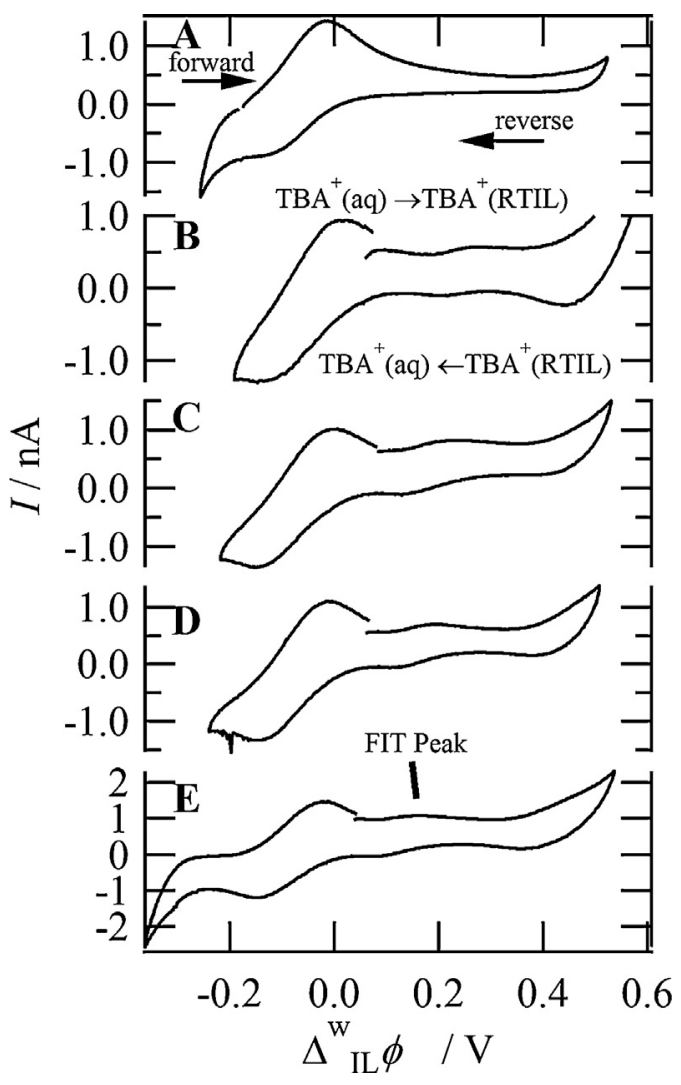

Fig. 4. Cyclic voltammograms (CV) obtained using Cell 2 with CMPO concentrations (y) of $0,27,48,62$, and $82 \mathrm{mM}$ for traces a, b, c, d, and e, respectively. Instrument parameters included a scan rate of $0.020 \mathrm{~V} \mathrm{~s}^{-1}$, an initial potential of $\sim 0.000 \mathrm{~V}$, and a potential range from approximately -0.250 to $0.575 \mathrm{~V}$. All CVs have been calibrated using the TATB assumption and the simple IT of $\mathrm{TBA}^{+} ; \Delta_{\mathrm{IL}}^{w} \phi_{\mathrm{TBA}^{+}}^{o^{\prime}}=-0.173 \mathrm{~V}$. 


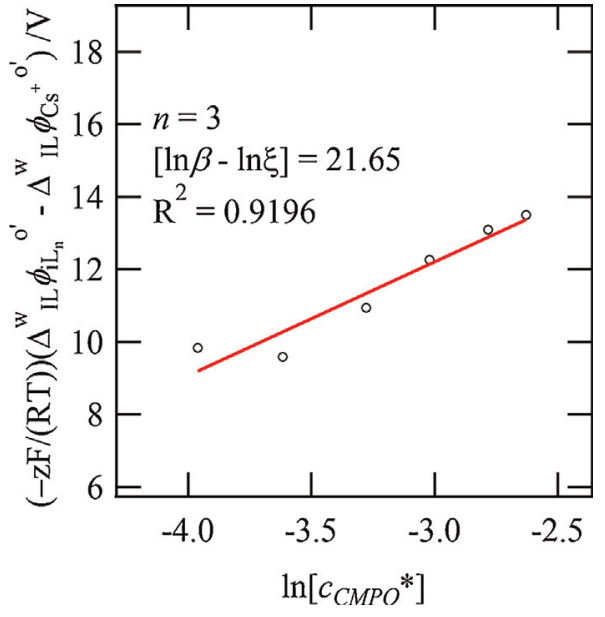

Fig. 5. Plot of $-z F /(R T)\left(\Delta_{\mathrm{IL}}^{w} \phi_{i L_{n}^{2+}}^{o^{\prime}}-\Delta_{\mathrm{IL}}^{w} \phi_{i^{2+}}^{o^{\prime}}\right)$ versus $\ln \left(c_{\mathrm{CMPO}, \mathrm{IL}}^{*}\right)$ with, inset, linear regression data for the slope (i.e., metal to ligand, $1: n$ ratio, $n=3$ ), $y$-intercept relationship $[\ln \beta+\ln \xi]=21.65$, and $R^{2}=0.9196$.

viscosity of the IL phase means the diffusion coefficient ratio found in the final term of Eq. (4) cannot be ignored. Previous studies of ferrocene diffusion in conventional electrochemistry [19] provide an estimate for the $\xi$ term with a $D_{\mathrm{IL}}$ equal to $5.0 \times 10^{-9} \mathrm{~cm}^{2} \mathrm{~s}^{-1}$, while $D_{w}$ was estimated to be $2.0 \times 10^{-5} \mathrm{~cm}^{2} \mathrm{~s}^{-1}$. Ferrocene, an organo-metallic compound, provides a facile analog for the metal ion-ligand complex and its diffusion coefficient was used as an approximation for the metal ion-ligand complex in the IL phase [19]. In this way, the overall complexation constant, for $\mathrm{CsCMPO}_{3}{ }^{+}$, was calculated to be $1.6 \times 10^{11}$. The relatively high stoichiometry, $n=3$, points to a possible octahedral ligand coordination geometry to reduce steric hinderance between ligands. This is a common metal ion:ligand ratio, along with $n$ equal to 2 , for alkali, alkali earth, and even heavier lanthanide metals undergoing complexation with CMPO [12,59].

Additionally, the $\mathrm{Cs}^{+}$wave is not as high as expected from relative high $\mathrm{Cs}^{+}$concentration. Scan rate experiments were then performed in order to determine the diffusion limiting species. For the case of $\mathrm{Cs}^{+}$-FIT, these data indicated that diffusion of the ligand to the interface is limiting. Details of these experiments have been provided in the electronic Supplementary Material.

Traditionally, metal ion extraction is evaluated through distribution ratios $[17,18,25]$, for example through the following:

$\delta_{\alpha}=\frac{\left[C s_{\mathrm{IL}}^{+}\right]}{\left[C s_{\mathrm{aq}}^{+}\right]}$

where a theoretical $\delta_{\alpha}$ can be determined using the kinetic/ thermodynamic parameters described herein and by Eq. (6):

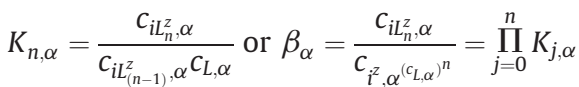

In this way, $\left(c_{L, \alpha}\right)^{n} \beta \approx \delta_{\alpha}$ and a general comparison can be made such that the distribution ratio for the w|DCE is only 2 at the highest ligand concentration, but $8.2 \times 10^{7}$ for the $\mathrm{w} \mid \mathrm{IL}$ case.

Interestingly, this result seems to demonstrate that Cs-FIT at the $\mathrm{w} \mid \mathrm{P}_{66614} \mathrm{~TB}$ interface using CMPO as a ligand, has some benefits relative to $\mathrm{w} \mid \mathrm{DCE}$ complexation. First, a lower applied potential to elicit metal ion complexation is a serious advantage as this means less energy needs to be applied to the system in order to achieve separation. Additionally, the high w|IL complexation constant reveals a substantial theoretical distribution coefficient, that also suggests improved efficiency.

However, 3 equivalents of ligand are required at the $\mathrm{w} \mid \mathrm{P}_{66614} \mathrm{~TB}$ interface versus only 1 at $\mathrm{w} \mid \mathrm{DCE}$. This is in contrast to recent studies surrounding rubidium [14] and strontium [12] which demonstrated a marked improvement for the $\mathrm{w} \mid \mathrm{IL}$ versus the $\mathrm{w} \mid$ DCE system. Critically, this points to a possible advantage in selectivity towards $\mathrm{Rb}^{+}$and $\mathrm{Sr}^{2+}$ versus $\mathrm{Cs}^{+}$that could be capitalized upon for SNF reclamation.

\section{Conclusions}

A model system for biphasic metal ion extraction was developed, comprised of the ionic liquid $\mathrm{P}_{66614} \mathrm{~TB}$. This IL was chosen owning to the excellent electrochemically stable cation/ anion pair that have been shown to possess weak ion-pair interactions and extreme hydrophobicity. FIT of $\mathrm{Cs}^{+}$with CMPO, a common ligand employed in industrial SNF recycling, was studied at an IL interface electrochemically and compared to the well established $w \mid D C E$ interface. The former elicited a metal ion to ligand $(1: n)$ stoichiometry of $1: 3$ with an overall complexation constant, $\beta$, estimated to be $1.6 \times 10^{11}$, while the latter demonstrated an $n$ equal to 1 with $\beta$ equal to 86.5. Previous results showed higher complexation constants for strontium and rubidi$\mathrm{um}$ at the $\mathrm{w} / \mathrm{P}_{66614} \mathrm{~TB}$ interface. This may suggest a higher selectivity for these ions over cesium using this biphasic system.

The CSCMPO stoichiometry at the w|DCE interface was confirmed through the use of ESI-MS and a 'shake-flask' experiment.

\section{Supplementary data}

Scan rate experiments at the $\mathrm{w} \mid \mathrm{IL}$ micro-interface.

\section{Acknowledgements}

We gratefully acknowledge the fruitful discussions with J. Clara Wren, Jamie Noël, David W. Shoesmith, Paul J. Ragogna, Doug Hairsine, Sherrie McPhee, and Marylou Hart along with their technical support. Many thanks to John Vanstone and Jon Aukima in Western Chemistry Electronic Shop for the fabrication/modification of the micropipette holder. This work was financially supported by the Ontario Research Fund, National Science and Engineering Research Council, Canada Foundation for Innovation, Ontario Innovation Trust, the Premier's Research Excellence Award, and the University of Western Ontario.

\section{Appendix A. Supplementary data}

Supplementary data associated with this article can be found, in the online version, at http://dx.doi.org/10.1016/j.aca.2014.03.012.

\section{References}

[1] B.M. Quinn, Z. Ding, R. Moulton, A.J. Bard, Langmuir 18 (2002) 1734.

[2] X. Lu, G. Burrell, F. Separovic, C. Zhao, The Journal of Physical Chemistry B 116 (2012) 9160.

[3] Y.-H. Tian, G.S. Goff, W.H. Runde, E.R. Batista, The Journal of Physical Chemistry B 116 (2012) 11943.

[4] T.R. Gore, T. Bond, W. Zhang, R.W.J. Scott, I.J. Burgess, Electrochemistry Communications 12 (2010) 1340.

[5] N. Nishi, Y. Yasui, T. Uruga, H. Tanida, T. Yamada, S.-I. Nakayama, H. Matsuoka, T. Kakiuchi, Journal of Chemical Physics 132 (2010) 164705/1.

[6] Y. Yasui, Y. Kitazumi, H. Mizunuma, N. Nishi, T. Kakiuchi, Electrochemistry Communications 12 (2010) 1479.

[7] Y. Yasui, Y. Kitazumi, N. Nishi, T. Kakiuchi, Journal of Chemical and Engineering Data 555 (2010) 4463.

[8] Y. Meng, L. Aldous, S.R. Belding, R.G. Compton, Chemical Communications (Cambridge, UK) 48 (2012) 5572.

[9] J. Lee, K. Murugappan, D.W.M. Arrigan, D.S. Silvester, Electrochimica Acta 101 (2012) 158.

[10] T. Zhang, H. Zhou, Angewandte Chemie-International Edition 51 (2012) 11062

[11] H. Yoon, G.H. Lane, Y. Shekibi, P.C. Howlett, M. Forsyth, A.S. Best, D.R MacFarlane, Energy \& Environmental Science 6 (2013) 979.

[12] T.J. Stockmann, Y. Lu, J. Zhang, H.H. Girault, Z. Ding, Chemistry: A European Journal 17 (2011) 13206. 
[13] X. Sun, H. Luo, S. Dai, Chemical Reviews 112 (2011) 2100.

[14] T.J. Stockmann, A.-M. Montgomery, Z. Ding, Analytical Chemistry 84 (2012) 6143.

[15] A.E. Visser, M.P. Jensen, I. Laszak, K.L. Nash, G.R. Choppin, R.D. Rogers, Inorganic Chemistry 42 (2003) 2197.

[16] N. Nishi, H. Murakami, S. Imakura, T. Kakiuchi, Analytical Chemistry 78 (2006) 5805.

[17] T. Vander Hoogerstraete, S. Wellens, K. Verachtert, K. Binnemans, Green Chemistry 15 (2013) 919.

[18] S. Dai, Y.H. Ju, C.E. Barnes, J. Chem. Soc, Dalton Transactions (1999) 1201.

[19] T.J. Stockmann, J. Zhang, J.C. Wren, Z. Ding, Electrochimica Acta 62 (2012) 8.

[20] T.J. Stockmann, Z. Ding, The Journal of Physical Chemistry B 116 (2012) 12826.

[21] W.E. Geiger, F. Barrière, Accounts of Chemical Research 43 (2010) 1030.

[22] A.J. Olaya, M.A. Méndez, F. Cortes-Salazar, H.H. Girault, Journal of Electroanalytical Chemistry 644 (2010) 60.

[23] R.J. LeSuer, C. Buttolph, W.E. Geiger, Analytical Chemistry 76 (2004) 6395.

[24] A.P. Paiva, P. Malik, Journal of Radioanalytical and Nuclear Chemistry 261 (2004) 485.

[25] T. Fujii, H. Yamana, M. Watanabe, H. Moriyama, Solvent Extraction and Ion Exchange 20 (2002) 151.

[26] Y. Qiao, B. Zhang, X. Zhu, T. Ji, B. Li, Q. Li, E. Chen, Y. Shao, Electroanalysis 24 (2013) 1080.

[27] T.J. Stockmann, Z. Ding, Analytical Chemistry 83 (2011) 7542.

[28] F. Reymond, G. Lagger, P.-A. Carrupt, H.H. Girault, Journal of Electroanalytical Chemistry 451 (1998) 59.

[29] P.D. Beattie, R.G. Wellington, H.H. Girault, Journal of Electroanalytical Chemistry 396 (1995) 317.

[30] S. Liu, Q. Li, Y. Shao, Chemical Society Reviews 40 (2011) 2236.

[31] Z. Samec, J. Langmaier, T. Kakiuchi, Pure and Applied Chemistry 81 (2009) 1473.

[32] H. Girault, in: A.J. Bard, C.G. Zoski (Eds.), Electroanalytical Chemistry (Electroanalytical Chemistry: A Series of Advances), CRC Press, 2010, pp. 1.

[33] Z. Samec, Electrochimica Acta 84 (2012) 21.

[34] P. Peljo, L. Murtomäki, T. Kallio, H.-J. Xu, M. Meyer, C.P. Gros, J.-M. Barbe, H.H. Girault, K. Laasonen, K. Kontturi, Journal of the American Chemical Society 134 (2012) 5974.

[35] S. Wu, B. Su, Chemistry: A European Journal 18 (2012) 3169.

[36] M.M. Hossain, H.H. Girault, H.J. Lee, Bulletin of the Korean Chemical Society 33 (2012) 1734.

[37] M.M. Hossain, C.S. Kim, H.J. Cha, H.J. Lee, Electroanalysis 23 (2011) 2049.

[38] E. Alvarez de Eulate, L. Serls, D.W.M. Arrigan, Analytical and Bioanalytical Chemistry 405 (2013) 3801.
[39] A. Gjelstad, H. Jensen, K.E. Rasmussen, S. Pedersen-Bjergaard, Analytica Chimica Acta 742 (2012) 10

[40] J.A. Ribeiro, F. Silva, C.M. Pereira, Analytical Chemistry 85 (2013) 1582.

[41] P. Sun, F.O. Laforge, M.V. Mirkin, Journal of the American Chemical Society 127 (2005) 8596.

[42] Z. Samec, D. Homolka, V. Mareček, Journal of Electroanalytical Chemistry and Interfacial Electrochemistry 135 (1982) 265.

[43] T. Kakiuchi, M. Senda, Journal of Electroanalytical Chemistry 300 (1991) 431.

[44] J. Langmaier, Z. Samec, Analytical Chemistry 81 (2009) 6382.

[45] J. Bruno, R.C. Ewing, Elements 2 (2006) 343.

[46] T.J. Stockmann, A.-M. Montgomery, Z. Ding, Journal of Electroanalytical Chemistry 684 (2012) 6.

[47] T.J. Stockmann, Z. Ding, Physical Chemistry Chemical Physics 14 (2012) 13949.

[48] M. Li, K. Aoki, J. Chen, T. Nishiumi, Journal of Electroanalytical Chemistry 655 (2011) 159.

[49] M. Satoh, K. Aoki, J. Chen, Langmuir 24 (2008) 4364.

[50] Y. Yoshida, Z. Yoshida, H. Aoyagi, Y. Kitatsuji, A. Uehara, S. Kihara, Analytica Chimica Acta 452 (2002) 149.

[51] T.J. Stockmann, A.-M. Montgomery, Z. Ding, Canadian Journal of Chemistry 90 (2012) 836.

[52] Y. Shao, M.D. Osborne, H.H. Girault, Journal of Electroanalytical Chemistry and Interfacial Electrochemistry 318 (1991) 101.

[53] A.J. Bard, L.R. Faulkner, Electrochemical Methods: Fundamentals and Applications, John Wiley, New York, 2001.

[54] R.S. Nicholson, I. Shain, Analytical Chemistry 36 (1964) 706.

[55] G. Taylor, H.H.J. Girault, Journal of Electroanalytical Chemistry and Interfacial Electrochemistry 208 (1986) 179.

[56] A.J. Parker, Electrochimica Acta 21 (1976) 671.

[57] K. Zhurov, E.J.F. Dickinson, R.G. Compton, The Journal of Physical Chemistry B 115 (2011) 6909.

[58] Y. Shao, A.A. Stewart, H.H. Girault, Journal of the Chemical Society, Faraday Transactions 87 (1991) 2593.

[59] E. Sharova, O. Artyushin, A. Turanov, V. Karandashev, S. Meshkova, Z. Topilova, I. Odinets, Central European Journal of Chemistry 10 (2012) 146.

[60] M.S. Hill, Annual Reports on the Progress of Chemistry Section A (Inorganic Chemistry) 108 (2012) 48.

[61] M.R. Antonio, M.L. Dietz, M.P. Jensen, L. Soderholm, E.P. Horwitz, Inorganica Chimica Acta 255 (1997) 13.

[62] S. Neander, U. Behrens, F. Olbrich, Journal of Organometallic Chemistry 604 (2000) 59.

[63] A. Sabela, V. Mareček, Z. Samec, R. Fuoco, Electrochimica Acta 37 (1992) 231.

[64] N.E. Holden, in: W.M. Haynes (Ed.), CRC Handbook of Chemistry and Physics, CRC Press/Taylor, Boca Raton, FL, 2011, pp. 11 